\title{
The Winter Concurrent Meridional Shift of the East Asian Jet Streams and the Associated Thermal Conditions
}

\author{
YAZHOU ZHANG \\ School of Atmospheric Sciences, Nanjing University, Nanjing, and Guchu Subdistrict Office, \\ Suqian National Economic and Technological Development Area, Suqian, China \\ PEIWEN YAN \\ School of Atmospheric Sciences, Nanjing University, Nanjing, China \\ ZHIJIE LIAO \\ People's Liberation Army 32033 Troop, Haikou, China \\ DANQING HUANG AND YAOCUN ZHANG \\ School of Atmospheric Sciences, Nanjing University, Nanjing, China
}

(Manuscript received 15 February 2018, in final form 20 January 2019)

\begin{abstract}
In this study, the concurrent meridional shift of the East Asian polar-front jet (EAPJ) and the East Asian subtropical jet (EASJ) and the associated thermal conditions have been investigated. The concurrent meridional shift is dominantly characterized by an out-of-phase shift of the two jets, as an equatorward shift of the EAPJ and a poleward shift of the EASJ, and vice versa. This shift is linked with the dipole surface air temperature (SAT) anomaly over the Eurasian continent and a La Niña-like sea surface temperature (SST) anomaly. Associated with the dipole SAT anomaly, the meridional temperature gradient (MTG) anomaly exhibits a tripole pattern from low to high latitudes over the Eurasian continent, as well as an enhanced maximum eddy growth rate and an anomalous divergence of Eliassen-Palm flux (E-P flux) over the regions between the EAPJ and EASJ. Additionally, the synoptic-scale transient eddy activities (STEA) significantly decrease over the high latitudes and enhance between the EAPJ and EASJ. All the anomalies would benefit the equatorward and poleward shift of the EAPJ and EASJ, respectively. The MTG, E-P flux and STEA anomalies are also indicated in that associated with the Niña-like SST anomaly. Particularly, the variations are evident in low latitudes. The pathway of the stationary Rossby wave activity flux anomalies shows an eastward Rossby wave packet propagation along the southern portion of the EAPJ is associated with the SAT anomaly and that along the northern portion of the EASJ is associated with the SST anomaly. The relative contributions of the two thermal conditions have emphasized the role of the dipole SAT anomaly, based on multilinear regression.
\end{abstract}

\section{Introduction}

In general, there are two branches of westerly jet streams in the upper troposphere over East Asia around the year, the East Asian polar-front jet (EAPJ) and the East Asian subtropical jet (EASJ). The EAPJ is located in the baroclinic zone, which is mainly formed by the eddy momentum flux convergence (Panetta 1993; Lee 1997).

Corresponding author: Dr. Danqing Huang, huangdq@nju. edu.cn
The EASJ is an important component of the global subtropical jet, which is driven by the angular momentum transport along the poleward shift of the Hadley cell (Held and Hou 1980; Hou 1998). The two jets are strongest in the boreal winter, lying zonally along the northern and southern flanks of the Tibetan Plateau, respectively (Xiao and Zhang 2012; Luo and Zhang 2015; Huang et al. 2017).

At the interannual scale, previous studies have emphasized the shift of the East Asian jet streams rather than the intensity variation in boreal winter ( $\mathrm{Lin}$ and $\mathrm{Lu}$ 2005). The shift can reflect the interactions among 
different circulation systems (Zhang et al. 2006; Schiemann et al. 2009) and therefore impact the local weather and climate as well as downstream regions (Jhun and Lee 2004; Li et al. 2004; Zhou and Yu 2005; Zhou and Zou 2010). On the one hand, the shift of the EAPJ can affect the variation of atmospheric circulation systems (e.g., the East Asia trough, Mongolian high pressure, and the blocking high) and therefore affect severe weather events, such as persistent low-temperature events and cold waves over East Asia (Zhang et al. 1997; D. Wang et al. 2009; Kuang et al. 2016). The seasonal evolution of the EAPJ is consistent with that of precipitation over eastern China (Zhang et al. 2008). On the other hand, the shift of the EASJ is highly associated with precipitation variations over China (Liao et al. 2004; Kuang and Zhang 2006; Dong et al. 2010; Ma et al. 2011; Shen et al. 2011; Xuan et al. 2011; Sun and Yang 2012; Lu et al. 2013). For example, the equatorward shift of the EASJ can affect the vertical momentum flux via the secondary circulation system and reinforce the water vapor flux transportation, and therefore enhance the precipitation over southern China (Zhang et al. 2009; Wang et al. 2011; Li and Zhang 2013).

Many factors can lead to the variations of the East Asian jet streams, such as the external forcing and internal atmospheric variability. There is some typical external forcing, such as the anomalous sea surface temperature (SST) over the western North Pacific (Yang et al. 2002; Lu et al. 2010), the anomalous snow cover over the Eurasian region (Yang et al. 2004; Chen and Sun 2003) and the heating and cooling over the Tibetan Plateau (Huang et al. 2015; Xue and Zhang 2017; Li et al. 2018). In general, changes of the thermal conditions may alter the meridional temperature gradients in the troposphere (Seidel et al. 2008; Si et al. 2009; Yim et al. 2016) that affect the EAPJ and EASJ (Huang et al. 2017) via the thermal wind relation (Zhang and Huang 2011). Huang et al. $(2017,2019)$ have shown that the combination of the negative phase of the interdecadal Pacific oscillation and the positive phase of the Atlantic multidecadal oscillation would enhance the meridional temperature gradient and westerlies over the region between the two jets, and therefore contribute to the equatorward shift of the EAPJ and the poleward shift of the EASJ. Besides the thermal conditions, the shift of the two jets is also influenced by the internal atmospheric variability [e.g., the synoptic-scale transient eddy activity (STEA)], based on the eddy-zonal flow feedback (Feldstein and Lee 1996; Carillo et al. 2000; Lorenz and Hartmann 2001, 2003; Eichelberger and Hartmann 2007; Ren et al. 2008; Li and Wettstein 2012). For example, the shift of the EAPJ is consistent with that of the STEA band over East Asia during the transition period from April to June (Ren et al. 2010). Xiang and Yang (2012) have shown that the transient eddy vorticity forcing could reinforce the meridional shift of the EASJ, favoring a positive feedback in the wave-flow interaction.

Recently, many studies have highlighted the concurrent variation of the two jets rather than the independent variation, since the concurrent variation can reflect the combined variation of the low- and highlatitude circulations and therefore result in severe weather and climate events (Liao and Zhang 2013), such as the dipole precipitation anomaly over eastern China (Li and Zhang 2014; Huang et al. 2014; Zhu et al. 2016), the decrease of the spring persistent rainfall after 1998 (Huang et al. 2015), variation of the East Asian winter monsoon (Luo and Zhang 2015), and the recent winter precipitation changes over eastern China (Huang et al. 2017). However, previous studies on the concurrent variation of the two jets mainly emphasized the intensity variation instead of the meridional shift variation. Some recent studies (Luo and Zhang 2015; Xue and Zhang 2017) have mentioned the variation of the meridional shift, but they do not separate the concurrent shift and the concurrent intensity variations. Moreover, the possible mechanism is still an open issue.

In all, we try to answer the following questions in this study: 1) What is the interannual variation of the concurrent meridional shift of the EAPJ and EASJ in the boreal winter? 2) What are the possible mechanisms for the concurrent meridional shift of the two jets?

The paper is organized as follows. The data and the methods are described in section 2. Section 3 presents the characteristics of the concurrent meridional shift of the EAPJ and EASJ. Possible mechanisms for the concurrent meridional shift of the two jets are proposed from the perspective of thermal conditions in section 4. Conclusions and discussion are provided in section 5 .

\section{Data and analysis methods}

\section{a. Data}

The datasets used in this study include the following products covering 63 boreal winters (DecemberFebruary) from 1951/52 to 2013/14:

1) The monthly and daily data from the National Centers for Environmental Prediction (NCEP)National Center for Atmospheric Research (NCAR) reanalysis (Kalnay et al. 1996), with a $2.5^{\circ} \times 2.5^{\circ}$ horizontal resolution and 17 levels in the vertical direction. The variables include the zonal wind, meridional wind, 
surface pressure, air temperature, and geopotential height. For comparison, the ECMWF interim reanalysis (ERA-Interim) during 1979-2014 with a $\sim 0.75^{\circ} \times 0.75^{\circ}$ horizontal resolution and eight levels (consistent with the NCEP-NCAR reanalysis datasets) in vertical direction is also used (Dee et al. 2011).

2) The global monthly SST from the Hadley Center Sea Ice and Sea Surface Temperature dataset (HadISST) with a resolution of $1^{\circ} \times 1^{\circ}$ (Rayner 2003).

3) The global monthly surface air temperature (SAT) from the Climatic Research Unit (CRU; Harris et al. 2014) and from the University of Delaware (https://www.esrl.noaa.gov/psd/data/gridded/data.UDel_ AirT_Precip.html) with a resolution of $0.5^{\circ} \times 0.5^{\circ}$.

\section{b. Methods}

We followed four steps to obtain the concurrent meridional shift of the two jets:

1) The active regions of the two jets are defined following Ren et al. (2011): a jet core is identified if the wind speed at $300 \mathrm{hPa}$ is higher than $30 \mathrm{~m} \mathrm{~s}^{-1}$ for any given day and grid point and the wind speed at the central point is larger than its eight surrounding points.

2) The location of the jet axis is represented by the latitude of the maximum westerly flow at each longitude, based on the winter-mean wind speed at $300 \mathrm{hPa}$ (Zhang et al. 2006).

3) The $300-\mathrm{hPa}$ jet axis anomaly is defined as the deviation from the position of the jet axis (Xiang and Yang 2012).

4) Following Xiang and Yang (2012), the 2.5-8-yr bandpass-filtered jet axis is used to emphasize the interannual variability. The empirical orthogonal function (EOF) analysis against the 2.5-8-yr bandpassfiltered jet axis anomaly along the longitude band $70^{\circ}-$ $110^{\circ} \mathrm{E}$ (where the active region of the two jets is detected in the first step) is performed to reveal the dominant interannual variation of the concurrent meridional shift of the EAPJ and EASJ.

The meridional temperature gradient over a tropospheric layer is estimated as $\Delta \bar{T} / a \Delta \phi$, where $\Delta \bar{T}$ is the difference of the vertically averaged temperature from the surface to $300 \mathrm{hPa}$ between two adjacent zonal bands with a latitude distance of $\Delta \phi$ within $20^{\circ}-70^{\circ} \mathrm{N}$ and $a$ is Earth's radius.

To understand the STEA variations associated with that of the jets, the maximum eddy growth rate (MEGR), the STEA kinetic energy $K_{e}$, and the EliassenPalm vector (E-P flux) are analyzed.

Hoskins and Valdes (1990) proposed that the midlatitude STEA was largely ascribed to the atmospheric baroclinicity, which can be measured by the MEGR (Eady 1949) with the following formula:

$$
\operatorname{MEGR}=0.31\left(\frac{f}{N}\right)\left(\frac{d V}{d z}\right),
$$

where $f$ refers to the Coriolis parameter, $N$ represents the Brunt-Väisälä frequency, $V$ denotes the horizontal wind velocity, and $z$ is the vertical height.

The intensity of $K_{e}$ is calculated as

$$
K_{e}=\frac{1}{2} \overline{\left(u^{\prime 2}+v^{\prime 2}\right)},
$$

where $u$ and $v$ refer to the zonal and meridional wind speed, respectively, the overbar denotes the time mean in the boreal winter, and the primes represent 2.5-8day perturbations by the bandpass filter (Murakami 1979).

The E-P flux is defined as

$$
\mathbf{E}=\left(\overline{v^{\prime 2}-u^{\prime 2}}, \overline{-u^{\prime} v^{\prime}}\right) .
$$

The signs in Eq. (3) have the same meaning as in Eq. (2). The divergence of $\mathbf{E}$ corresponds to the forcing on the horizontal circulation by enhancing the mean westerly flow, and vice versa (Hoskins et al. 1983).

To quantitatively estimate the horizontal propagation of stationary Rossby waves, the wave activity flux vector $\mathbf{W}$ is calculated in the expression formulated by Takaya and Nakamura (2001):

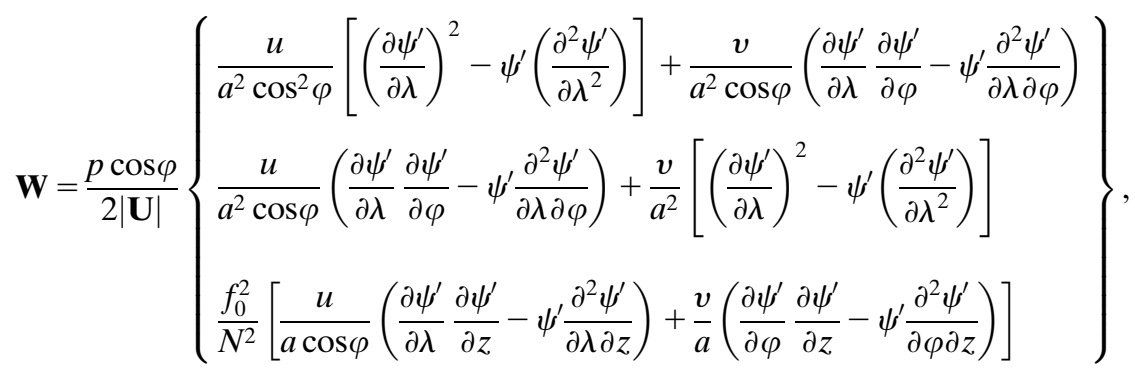




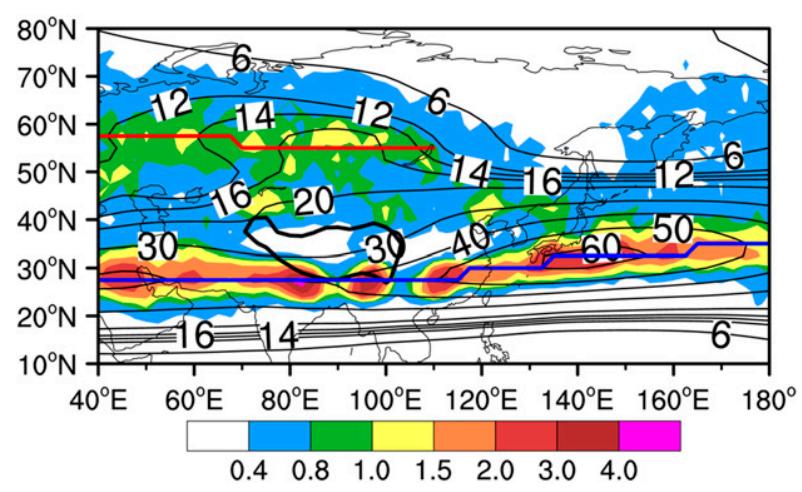

FIG. 1. The climatological zonal wind (contours; $\mathrm{m} \mathrm{s}^{-1}$ ) and horizontal jet core (shaded) at $300 \mathrm{hPa}$ in the boreal winter during 1951/52-2013/14. The red (blue) solid line indicates the climatological jet axis of the EAPJ (EASJ) at $300 \mathrm{hPa}$. The topography of the Tibetan Plateau is denoted by the thick black line.

where $\mathbf{U}=(u, v)$ is horizontal wind vector, $p=$ (pressure $/ 1000 \mathrm{hPa})$ is the normalized pressure, and $\psi^{\prime}$ is the streamfunction anomaly. This flux is independent of wave phases and parallels the group velocity in a zonally varying basic flow.

Correlation and regression analyses are also applied in this study. To quantify the relative contribution of the two thermal conditions to the concurrent shift of the two jets, multilinear regression is used. The statistical significance of the regression coefficient is assessed using a Student's $t$ test at the $95 \%$ confidence level.

\section{The concurrent meridional shift of the EAPJ and EASJ}

The horizontal distribution of the climatological occurrence frequency of the jet core at $300 \mathrm{hPa}$ in the boreal winter is shown in Fig. 1. The jet cores are located at the northern and southern flanks of the Tibetan Plateau, corresponding to the active regions of the EAPJ and EASJ, respectively (Pena-Ortiz et al. 2013; Luo and Zhang 2015; Huang et al. 2017). Particularly, the jet cores occur more frequently over the EASJ region than the EAPJ region. Following Liao and Zhang (2013) and Huang et al. (2017), $70^{\circ}-110^{\circ} \mathrm{E}$ is chosen as the active region of the EAPJ and EASJ in boreal winter to investigate the concurrent meridional shift of the two jets.

The EOF analysis is used to capture the dominant concurrent meridional shift of the two jets. The first leading EOF mode explains $66 \%$ of the total variance, revealing that the EAPJ and EASJ have experienced a prominent meridional shift (Fig. 2a). As shown in Fig. 2a, an obvious out-of-phase variation in the
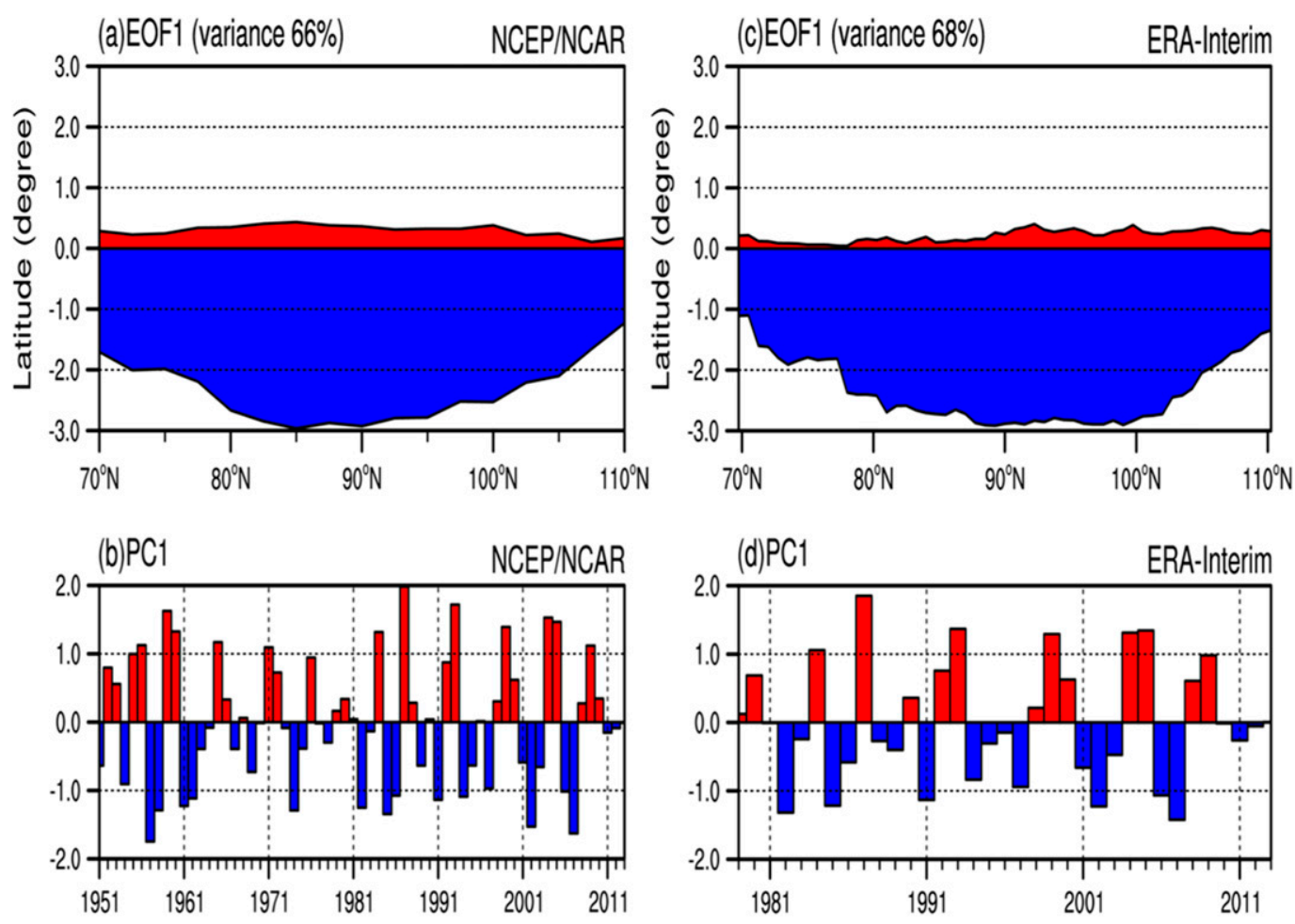

FIG. 2. (a),(c) The first EOF mode of the EAPJ (blue) and EASJ (red) axis anomalies at $300 \mathrm{hPa}$ in the boreal winter and (b),(d) the time series of the corresponding principal component of the first EOF mode from (left) NCEP-NCAR for 1951-2013 and (right) ERA-Interim for 1979-2013. 
meridional shift of the EAPJ and EASJ is detected. This suggests a short distance between the EAPJ and EASJ (short-distance case) or a far distance between them (far-distance case). A repeat analysis of the ERAInterim datasets for the period of 1979-2013 further confirms the result, which is shown in Figs. $2 \mathrm{c}$ and $2 \mathrm{~d}$. Although the time period is not consistent in the two reanalysis datasets, similar leading EOF patterns have been detected by both datasets. The differences between the two reanalysis datasets are largely due to differences of the model resolution (figure omitted).

To examine the concurrent meridional shift of the two jets, the regressions of zonal winds against the normalized PC1 are shown in Fig. 3. The latitudinal cross section of the westerly anomaly demonstrates a tripole pattern around the climatological EAPJ and EASJ axes at $300 \mathrm{hPa}$ from $10^{\circ}$ to $80^{\circ} \mathrm{N}$. Two negative wind anomalies are located at $\sim 20^{\circ}$ and $65^{\circ} \mathrm{N}$, and a positive zonal wind anomaly is located at $\sim 45^{\circ} \mathrm{N}$ (Fig. 3a). The horizontal distribution of the regressed zonal wind anomalies at $300 \mathrm{hPa}$ is shown in Fig. $3 \mathrm{~b}$, indicating a notable anomalous cyclone and an anomalous anticyclone around the EAPJ and EASJ axes, respectively. Correspondingly, the EAPJ and EASJ would shift equatorward and poleward, respectively. We also noticed that the concurrent shift of the two jets has mainly appeared over the Tibetan Plateau (Fig. 3b). This may imply the dominant role of the large-scale topography on the concurrent meridional shift of the two jets (Huang et al. 2015; Xue and Zhang 2017). In particular, the intensity of the wind anomaly around the EAPJ axis is substantially larger than that around the EASJ axis, corresponding to the far greater shift of the EAPJ than the EASJ (Fig. 2a). Thus, PC1 can reflect the concurrent meridional shift of the EAPJ and EASJ (the out-ofphase shift of the two jets) at the interannual time scale. The normalized PC1 is defined as the jet location index (JLI) in this study.

\section{The possible mechanisms for the concurrent meridional shifts of the EAPJ and EASJ}

In this section, we investigated the possible mechanisms of the interannual variation of the concurrent meridional shift of the two jets from the perspective of thermal conditions, including the variation of the SAT and SST. As mentioned in section 1, the thermal conditions would affect the meridional temperature gradient and STEA, and therefore impact the concurrent shift of the two jets. Thus, we first detected the significant thermal anomalies and then analyzed the associated meridional temperature gradient and STEA anomalies. Although there are two types of the concurrent variability (a)
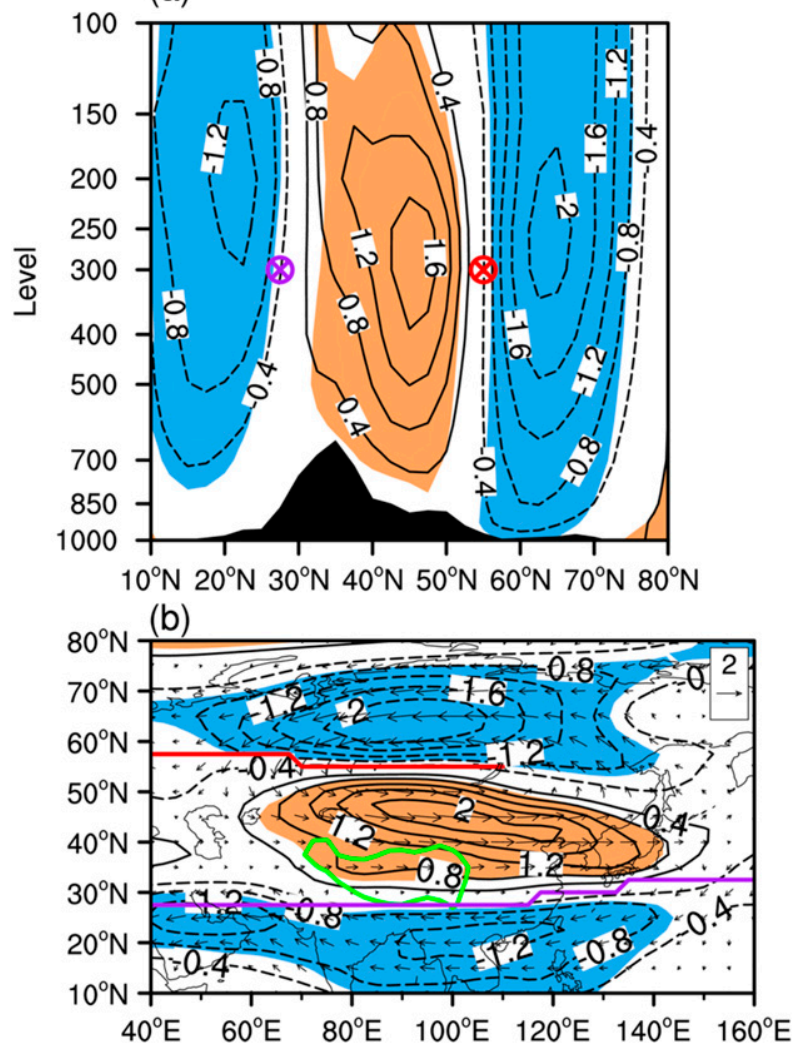

FIG. 3. (a) Latitudinal cross section of zonal wind anomalies (contours; $\mathrm{m} \mathrm{s}^{-1}$ per unit index) averaged over $70^{\circ}-110^{\circ} \mathrm{E}$ regressed against the JLI in the boreal winter. The red (purple) circle indicates the climatological position of the EAPJ (EASJ) axis at $300 \mathrm{hPa}$. The black shaded area shows the topography of the Tibetan Plateau. (b) The horizontal distribution of zonal wind anomalies (contours; $\mathrm{m} \mathrm{s}^{-1}$ per unit index) and wind velocity anomalies (vectors; $\mathrm{m} \mathrm{s}^{-1}$ per unit index) at $300 \mathrm{hPa}$ regressed against the JLI in the boreal winter. Areas of statistical significance exceeding the $95 \%$ confidence level are shaded. The red (purple) solid line indicates the climatological horizontal jet axis of the EAPJ (EASJ) at $300 \mathrm{hPa}$. The topography of the Tibetan Plateau is denoted by the thick green line.

(short-distance case and far-distance case), they largely mirror each other. Thus, we only analyzed the circulations associated with the positive PC1, which favors the equatorward shift of the EAPJ and the poleward shift of the EASJ (short-distance case).

\section{a. The associated SAT variations}

The regression of SAT against the JLI is shown in Fig. 4. Because of the uncertainties of the SAT over the Tibetan Plateau (Zhu et al. 2017), we chose two datasets to analyze. They show consistent results: two significant SAT anomalies with an out-of-phase variation are located over the Tibetan Plateau and mid- to high-latitude areas, with a warm anomaly over the Tibetan Plateau 

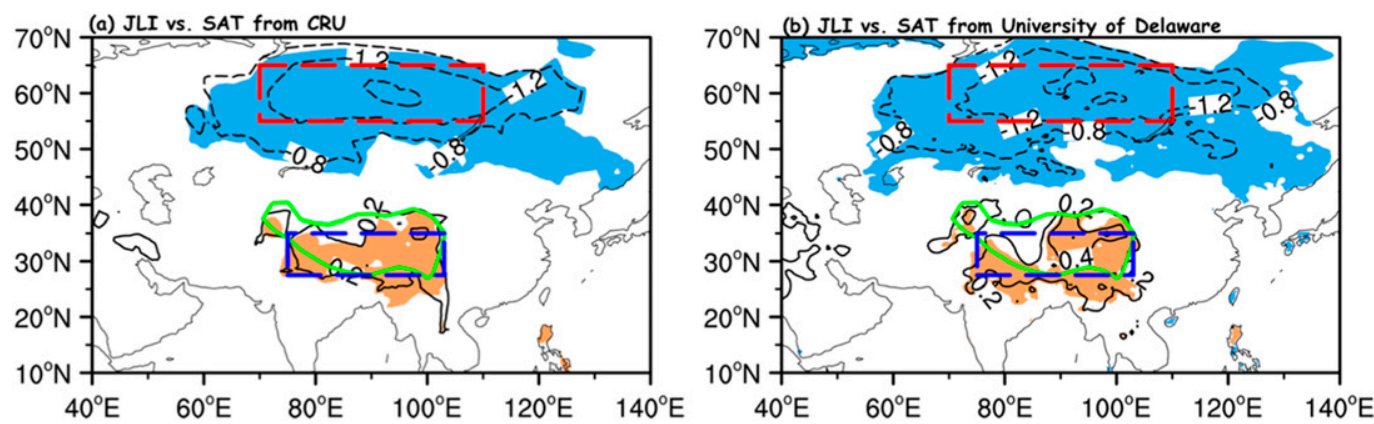

FIG. 4. Regressions of the surface air temperature against the JLI in the boreal winter (contours; ${ }^{\circ} \mathrm{C}$ per unit index) from (a) CRU and (b) the University of Delaware. Areas of statistical significance exceeding the $95 \%$ confidence level are shaded. The dashed red and blue boxes indicate the key regions for calculating the surface air temperature index (SATI). The topography of the Tibetan Plateau is denoted by the thick green line.

and a cool anomaly over mid- to high latitudes. We selected the SAT over two significant regions (red and blue boxes in Fig. 4) to define this out-of-phase SAT variation as the normalized SAT variation index (SATI), with the following formula:

$$
\begin{aligned}
\text { SATI }= & \operatorname{SAT}\left[27.5^{\circ}-35^{\circ} \mathrm{N}, 75^{\circ}-103^{\circ} \mathrm{E}\right] \\
& -\operatorname{SAT}\left[55^{\circ}-65^{\circ} \mathrm{N}, 70^{\circ}-110^{\circ} \mathrm{E}\right] .
\end{aligned}
$$

The square brackets denote the regionally averaged SAT. A large SATI indicates a relatively cooler condition over the EAPJ region than the EASJ region. The regressed wind anomalies against the SATI have been shown in Fig. 5. A significant negative-positive-negative wind anomaly is located from the low to high latitudes, which resembles the zonal wind anomaly associated with the JLI (Fig. 3). This suggests that the SATI can explain the dominant interannual variation of the meridional shift of two jets.

Regression of the meridional temperature gradient against the SATI is shown in Fig. 6. A significant tripole meridional temperature gradient anomaly pattern exists from $20^{\circ}$ to $80^{\circ} \mathrm{N}$. The positive anomalies are over the northern side of the EAPJ and southern side of the EASJ, while the negative anomaly lies between the regions of the EAPJ and EASJ axis. In particular, the meridional temperature gradient anomalies are more significant over the high latitudes than that over the low latitudes. Since the climatological meridional temperature gradient is negative over the Northern Hemisphere due to the decreasing temperature from south to north, the negative (positive) meridional temperature gradient anomaly would strengthen (weaken) winds there, based on the thermal wind relation (Zhang et al. 2006). The anomalous meridional temperature gradient would lead to a westerly acceleration over the region between the EAPJ and EASJ axis, indicating the equatorward shift of the EAPJ and a poleward shift of the EASJ.

Figure 7 shows the regressed MEGR (green contours), the $K_{e}$ (shading), and the E-P flux divergence (black contours) anomalies against the SATI. The positive MEGR anomaly is located between the axis of the EAPJ and EASJ in the lower troposphere

(a)
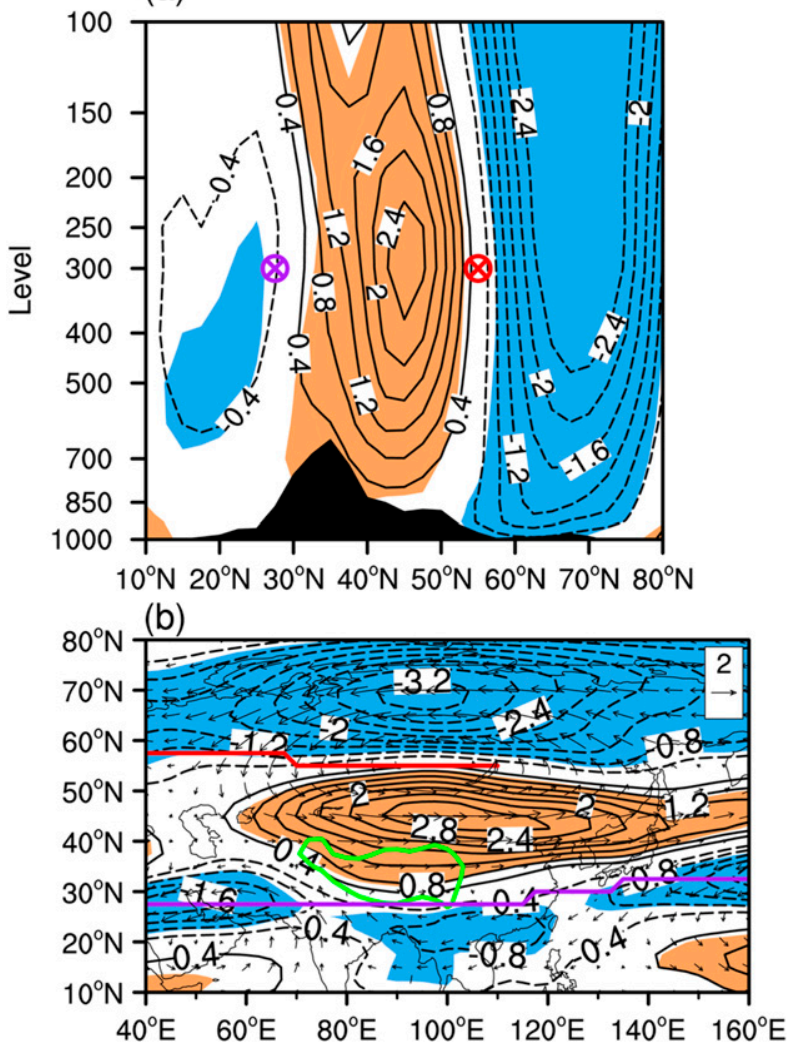

FIG. 5. As in Fig. 3, but for the latitudinal cross section of the zonal wind anomalies (contours; $\mathrm{m} \mathrm{s}^{-1}$ per unit index) averaged over $70^{\circ}-110^{\circ} \mathrm{E}$ regressed against the SATI in the boreal winter. 


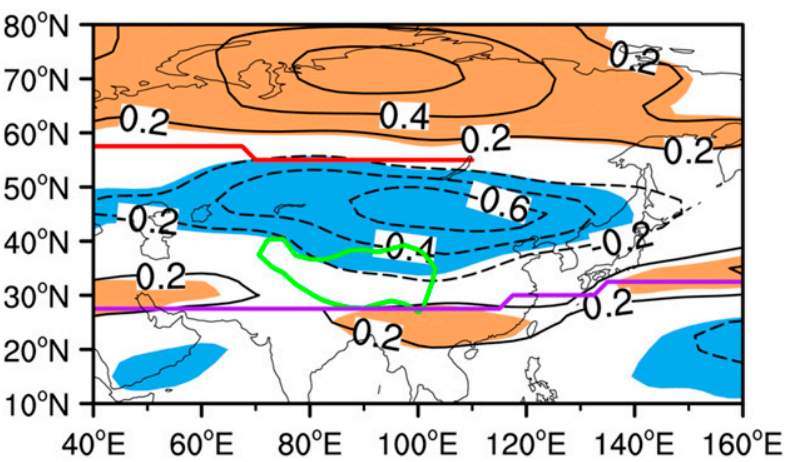

FIG. 6. Regressions of the meridional temperature gradient (MTG) (contours; $10^{-6}{ }^{\circ} \mathrm{C} \mathrm{m}^{-1}$ per unit index) integrated from the surface to $300 \mathrm{hPa}$ against the SATI in the boreal winter. Areas of statistical significance exceeding the $95 \%$ confidence level are shaded. The red (purple) line indicates the climatological horizontal jet axis of the EAPJ (EASJ) at $300 \mathrm{hPa}$. The topography of the Tibetan Plateau is denoted by the thick green line.

$(850-1000 \mathrm{hPa})$, where the sensitive region of the MEGR is located (Lunkeit et al. 1998). This positive MEGR anomaly would benefit the westerly flow between the two jets, possibly associated with the increased horizontal temperature gradients (Lehmann et al. 2014). Meanwhile, the large negative $K_{e}$ anomaly is mainly located at the northern side of the EAPJ axis at $\sim 250 \mathrm{hPa}$, while the small positive $K_{e}$ anomaly is at the northern side of the EASJ axis at $200 \mathrm{hPa}$. These would benefit the equatorward shift of the EAPJ and the poleward shift of the EASJ. In fact, $K_{e}$ anomalies over the EASJ region are not as significant as those over the EAPJ region. Since the EAPJ is mainly formed by the eddy momentum flux convergence (Panetta 1993), the equatorward shift of EAPJ is more consistent with the variation of STEA at the interannual time scale than that of poleward shift of the EASJ ( $\mathrm{Li}$ and Wettstein 2012). Based on the theory of wave-flow interaction, variation of the time-mean flow induced by the STEA can be identified by the divergence of the E-P flux (Gong et al. 2011). Generally, the divergence region is related to the acceleration of mean westerly flow and the convergence responds to the westerly deceleration (James 1994, 78-79; Hoskins et al. 1983). As shown in Fig. 7, there are two significant meridional dipole patterns of the divergence anomalies of E-P flux (black contour) along the EAPJ axis and the EASJ axis. Associated with the SATI, a significant divergence (convergence) anomaly is located at the southern (northern) side of the EAPJ axis, indicating the energy conversion from the STEA to the mean westerly flow (from the mean westerly flow to the STEA), where the

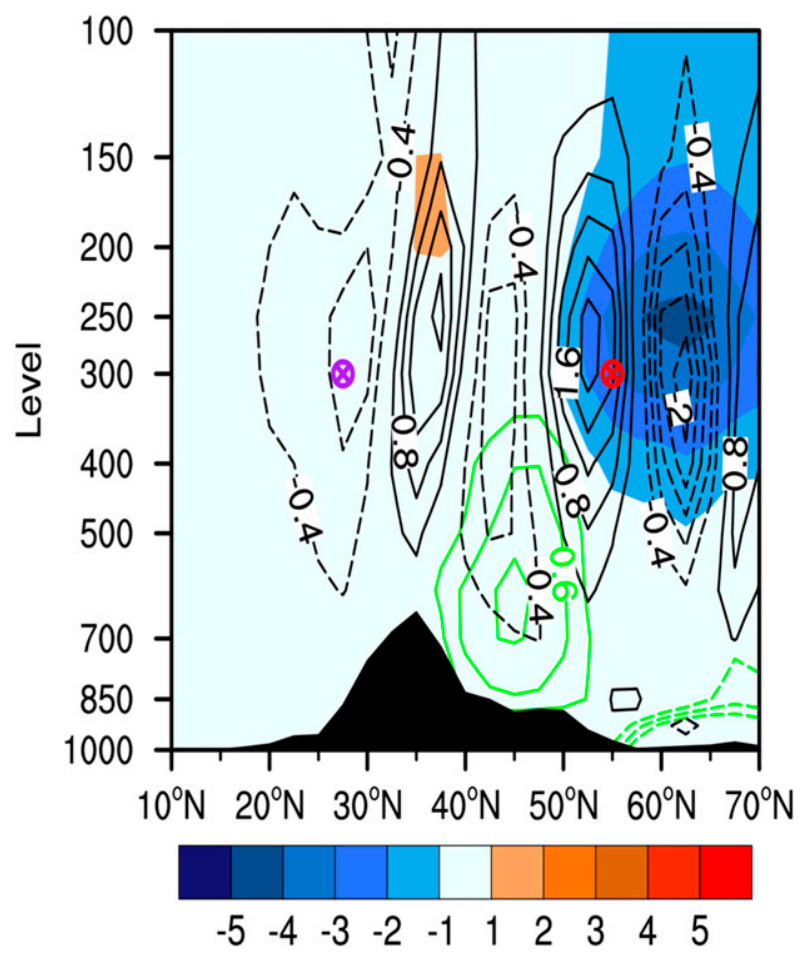

FIG. 7. Latitudinal cross section of the regressed maximum eddy growth rate (MEGR) anomalies (green contours; $10^{-1}$ day $^{-1}$ per unit index), the $K_{e}$ anomalies (shaded; $\mathrm{m}^{2} \mathrm{~s}^{-2}$ per unit index), and the divergence anomalies of E-P flux (black contours; $10^{-6} \mathrm{~m} \mathrm{~s}^{-2}$ per unit index), averaged over $70^{\circ}-110^{\circ} \mathrm{E}$ against the SATI in the boreal winter. The red (purple) circle indicates the climatological position of the EAPJ (EASJ) axis. The black shaded area indicates the topography of the Tibetan Plateau.

westerly flow strengthens (weakens) (Huang et al. 2014). Similarly, a significant divergence (convergence) anomaly is located at the northern (southern) side of the EASJ axis, and therefore results in the poleward shift of the EASJ. Note that we should not ignore the weak convergence anomaly along $40^{\circ}-50^{\circ} \mathrm{N}$, which may reduce the westerly flow. However, the enhanced MEGR over the region, combined with the two strong divergence anomalies of E-P flux along $30^{\circ}$ and $50^{\circ} \mathrm{N}$, may enhance the westerly flow there.

\section{b. The associated SST variations}

To find significant SST anomalies associated with the concurrent meridional shift of the two jets, the regression of SST against the JLI is shown in Fig. 8. A significant negative SST anomaly is located over the tropical central-eastern Pacific, which resembles the La Niña-like SST anomaly. To investigate the impact of the SST anomaly on the maintenance of the thermal and transient eddy effects associated with the concurrent meridional shift of the EAPJ and EASJ, a normalized SST variation index (SSTI) is defined as follows: 


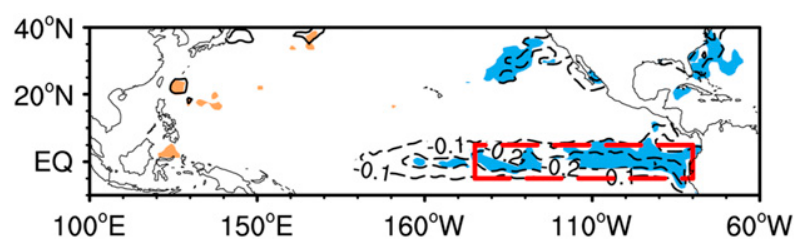

FIG. 8. Regressions of the SST (contours; ${ }^{\circ} \mathrm{C}$ per unit index) against the JLI in boreal winter. Areas of statistical significance exceeding the $95 \%$ confidence level are shaded. The dashed red box indicates the key region for calculating the sea surface temperature index (SSTI).

$$
\operatorname{SSTI}=-\operatorname{SST}\left[5^{\circ} \mathrm{S}-5^{\circ} \mathrm{N}, 80^{\circ}-145^{\circ} \mathrm{W}\right]
$$

The square brackets denote the regional averaged SST. Similarly, to further examine the associated wind anomalies, the zonal wind anomalies regressed against the SSTI are shown in Fig. 9. Although the anomaly in the high latitudes is weak, the wind anomalies are consistent with those are shown in Fig. 3, indicating the equatorward shift of the EAPJ and the poleward shift of the EASJ.

(a)
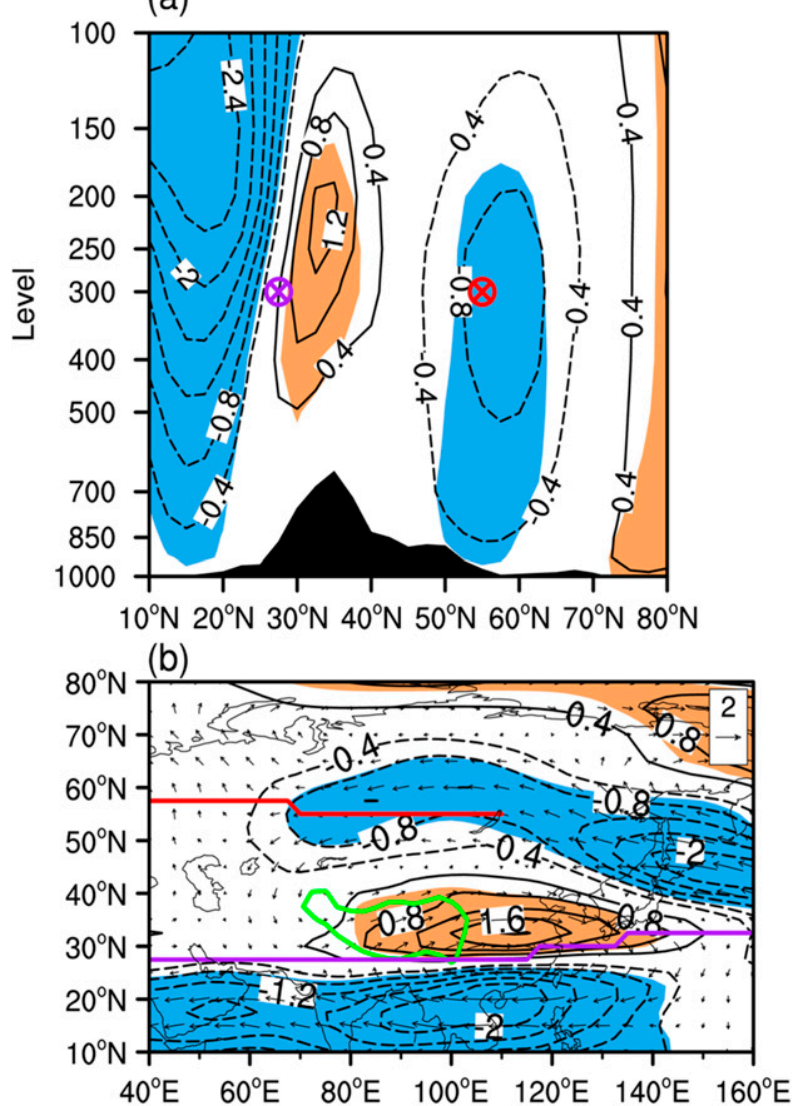

FIG. 9. As in Fig. 3, but for the regressions against the SSTI in boreal winter.

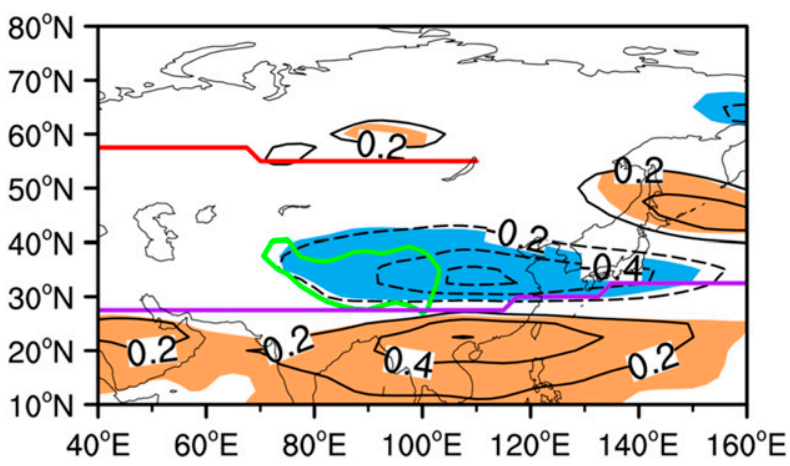

FIG. 10. As in Fig. 6, but for the regressions against the SSTI in boreal winter.

Figure 10 shows the regression of the meridional temperature gradient anomaly against the SSTI. A significant meridional dipole anomaly is along the EASJ axis, with a negative meridional temperature gradient anomaly over the northern part of the EASJ. This would enhance the westerly flow there via the thermal wind relation. A small positive meridional temperature gradient anomaly can also be observed along the northern side of the EAPJ axis, which would reduce the westerly flow there. It suggests that the La Niña-like SST anomaly may be more closely related to the meridional shift of the EASJ than of the EAPJ. Figure 11 shows the regressed MEGR (green contour), the $K_{e}$ (shading) and the E-P flux divergence (black contour) anomalies against the SSTI. Negative MEGR and Ke anomalies are along the southern side of the EASJ, and therefore

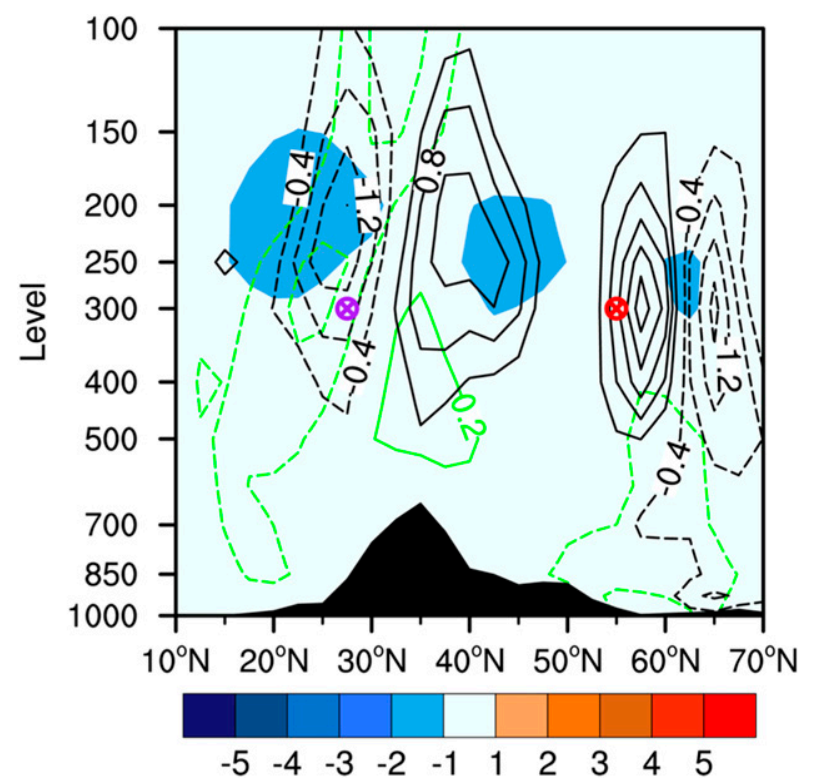

FIG. 11. As in Fig. 7, but for the regressions against the SSTI in boreal winter. 
(a) TN-flux \& Z $300 \mathrm{hPa}$ SATI

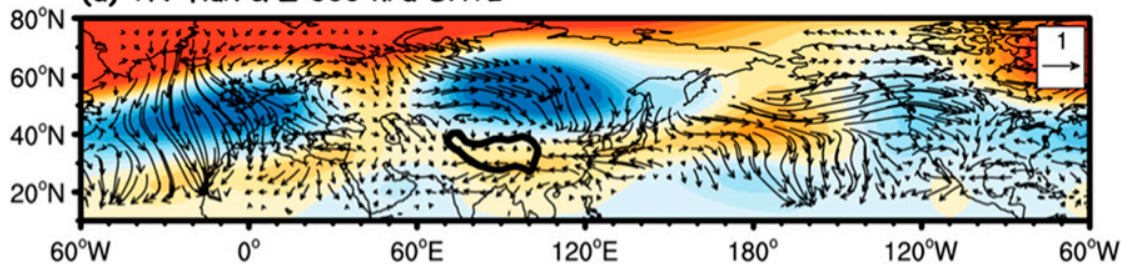

(b) TN-flux \& Z $300 \mathrm{hPa}$ SSTI

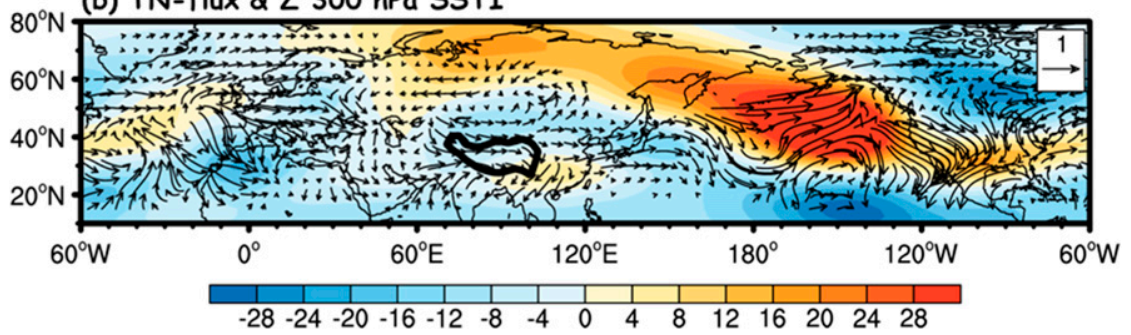

FIG. 12. Regressions of geopotential height (shaded; gpm per unit index) and wave activity flux (vectors; $\mathrm{m}^{2} \mathrm{~s}^{-2}$ per unit index) at $300 \mathrm{hPa}$ against the (a) SATI and (b) SSTI in boreal winter.

could reduce the westerly flow there. Two divergence anomalies of E-P flux are also found along the northern part of the EASJ axis and along the EAPJ axis, suggesting that the EAPJ would be enhanced and the EASJ would shift poleward.

We should notice that some previous studies have indicated the possible linkage between the SST variation over the eastern equator Pacific and the jet variations. For example, Huang et al. (2014) found that the La Niña-like SST anomaly would intensify the Walker circulation in the boreal summer, which could influence cyclone anomaly over the western Pacific (Wang et al. 2000). Correspondingly, the convective activities triggered over the western Pacific would benefit the meridional teleconnection and therefore affect the EASJ (Lu 2004). Sakai and Kawamura (2009) have revealed that the ENSO-related tropical convective forcing would affect the East Asian jet streams in the boreal winter, via the stationary Rossby wave propagation along the South Asian waveguide. Wang et al. (2000) and Zhang et al. (1996) also proposed the mechanisms that describe how the tropical SST anomalies affect the East Asian circulations, via the Pacific-East Asian teleconnection. As shown in Figs. $5 \mathrm{~b}$ and $5 \mathrm{c}$ in Wang et al. (2000), a giant cyclonic anomaly is located over Southeast Asia for El Niño composites. Consequently, the anomalous easterly wind along $30^{\circ}-40^{\circ} \mathrm{N}$ would weaken the westerly flow there (Luo and Zhang 2015). Since El Niño and La Niña composites largely mirror each other (Wang et al. 2000), atmospheric circulation anomalies show an anticyclonic pattern over Southeast Asia associated with La Niña events (Wang et al. 2000). Associated with the anticyclonic anomaly, the EAPJ and EASJ would exhibit an equatorward shift and a poleward shift, respectively, which is consistent with the regressed wind anomalies (Fig. 9).

c. The Rossby wave propagations associated with the SAT and SST variations

Sections $4 \mathrm{a}$ and $4 \mathrm{~b}$ show the possible linkages between the SAT and the SST variation and the meridional variation of the EAPJ and the EASJ, via the modulation of the meridional temperature gradient, MEGR, $K_{e}$, and E-P flux. Since the external forcing (SAT and SST variation) may generate the planetary wave modulations, we further investigated the possible propagation by analyzing the stationary Rossby wave activity fluxes and the geopotential anomaly fields in the entire extratropical Northern Hemisphere regressed against the SATI and SSTI ( Fig. 12).

Associated with the SATI (Fig. 12a), wave activity flux anomalies extend eastward from the Barents Sea $\left(70^{\circ} \mathrm{N}, 40^{\circ} \mathrm{E}\right)$ to East Asia along $50^{\circ}-55^{\circ} \mathrm{N}$, that is, the southern portion of the EAPJ. This high-to-midlatitude wave train is characterized by positive geopotential height anomalies over the Barents Sea and a negative anomaly over northern Asia. Modulated by the Arctic Oscillation, the Arctic sea ice could influence the jet variabilities by varying the thermal conditions (Honda et al. 2009; Mori et al. 2014). Associated with the SSTI (Fig. 12b), wave activity flux anomalies extend eastward from North Africa $\left(40^{\circ} \mathrm{N}, 20^{\circ} \mathrm{E}\right)$ to East Asia along the $40^{\circ} \mathrm{N}$, that is, the northern portion of the EASJ. However, the SSTI-related wave train is weaker than the SATI-relative one, as the largest wave activity fluxes anomalies are located over the North Pacific. 
(a)Z500

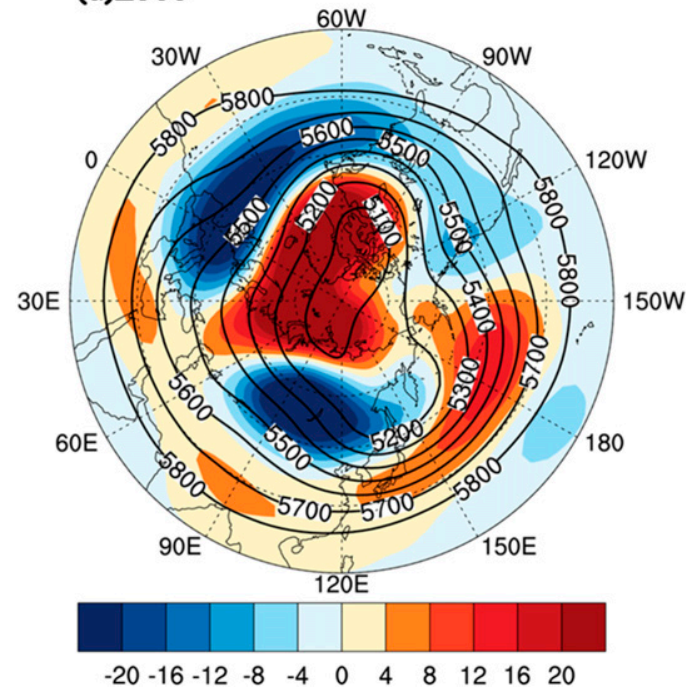

(b) SLP

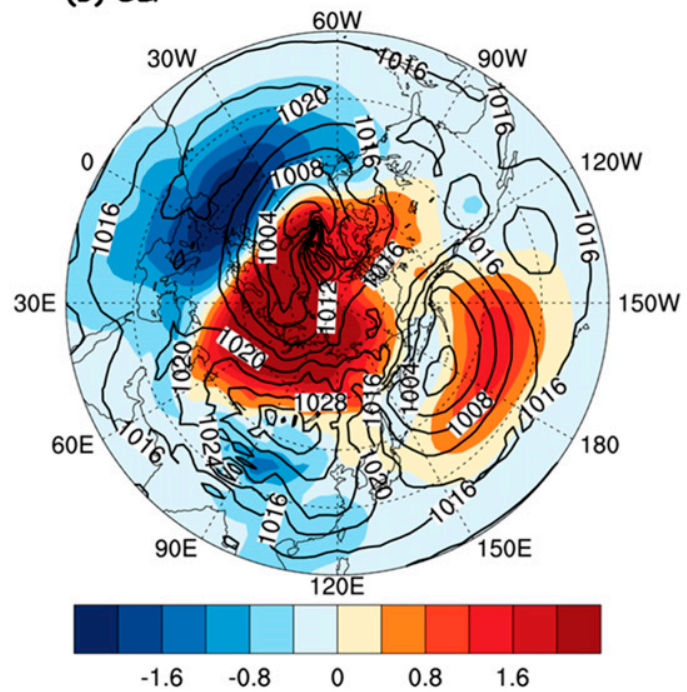

FIG. 13. Regressions of (a) geopotential height (shaded; gpm per unit index) at $500 \mathrm{hPa}$ and (b) sea level pressure (shaded; hPa per unit index) against the SATI in boreal winter. The black lines are the climatological-mean geopotential height at $500 \mathrm{hPa}$ in (a) and the sea level pressure in (b).

The geopotential height anomalies are quite consistent, indicating the negative height anomalies (anomalous cyclone) over northern Asia and the positive height anomalies (anomalous anticyclone) over the southern Tibetan Plateau and high latitudes. Associated with the cyclonic and anticyclonic anomalies, the EAPJ and EASJ would exhibit an equatorward and a poleward shift, respectively. These wind anomalies are consistent with the regressed wind anomalies against the SATI (Fig. 5) and SSTI (Fig. 9).

\section{d. The relative contribution of the $S A T$ and $S S T$ variations}

To confirm the results, we have repeated all the analyses above using the ERA-Interim datasets (figures omitted), and the results are similar. Thus, we conclude that both the SATI and SSTI would affect the out-ofphase shift of the two jets. To quantify the contribution of the SATI and SSTI to the concurrent meridional shift of the two jets, we performed a multilinear regression. This method is acceptable because the correlation of the two time series of the SATI and SSTI is weak, with a correlation coefficient of 0.0757 . The multilinear regression equation is JLI $\approx 0.493 \times$ SATI $+0.168 \times$ SSTI. The skill for this regression reaches 0.74 . Since the regression coefficient of the SATI is higher than that of the SSTI, the multilinear regression indicates that the dipole SAT anomaly is more important than the negative SST anomaly over the central-eastern Pacific with regard to the impact on the concurrent meridional shift of the two jets.
Previous studies have mentioned the changes of the EAPJ and EASJ in general circulations associated with the East Asian winter monsoon, such as the geopotential height fields (L. Wang et al. 2009; Huang et al. 2012; Liu et al. 2014; Oh et al. 2017). For example, L. Wang et al. (2009) indicated that the variation of the East Asian trough axis is closely associated with the midlatitude baroclinic process and therefore represents the intensity of the EAPJ. Luo and Zhang (2015) mentioned that a southward shift of the EAPJ occurs with northwestward displacement of the Siberian high and an enhanced northern East Asian trough. To give a full picture of present results, we further examined the geopotential height at $500 \mathrm{hPa}$ and the sea level pressure associated with the SATI (Fig. 13). The regressed 500 -hPa geopotential height anomaly (Fig. 13a) increases over the low-to-midlatitude region around $10^{\circ}-$ $30^{\circ} \mathrm{E}$ and over the Arctic region but decreases over the Eurasian continent. The horizontal structure of the geopotential height anomaly shows a clear wave train pattern at $500 \mathrm{hPa}$. The wave train may be interpreted as quasi-stationary Rossby waves trapped on the East Asian jet waveguide, particularly for the EASJ (Branstator 2002; Watanabe 2004; Takaya and Nakamura 2013). Combined with the wave activity flux variations observed from the Barents Sea to Siberia (Fig. 12), some upstream factors may lead to the change of surface air temperature and temperature gradient over Siberia, and therefore affect the variation of the two jet streams, via the hemispheric-scale circulation anomaly (Fig. 13). Similarly, the regressed sea level 
pressure anomalies resemble a negative phase of the Arctic Oscillation (Xue and Zhang 2017). The correlation coefficient between the SATI and the Arctic Oscillation index (http://www.cpc.ncep.noaa.gov/products/ precip/CWlink/daily_ao_index/ao.shtml) is -0.24 , which is significant at the $90 \%$ confidence level. Watanabe (2004) also revealed that on the interannual time scale, the North Atlantic Oscillation (NAO) signal is collocated with a wave train along the EASJ. These results have established a possible linkage among the SATI, the Arctic Oscillation, and the meridional shift of the two jets in the boreal winter, but further investigation is needed.

\section{Conclusions and discussion}

In this study, the interannual variability of the concurrent meridional shift of the EAPJ and the EASJ in the boreal winter is investigated. This shift is revealed by the leading EOF of the filtered 300-hPa EAPJ and EASJ axis anomalies. At the interannual time scale, the two jets exhibit a prominent meridional shift between $70^{\circ}$ and $110^{\circ} \mathrm{E}$, indicating an obvious out-of-phase variation of the two jets. This variation suggests that as the EAPJ shifts poleward, the EASJ shifts equatorward, and vice versa.

Two significant thermal conditions, the dipole SAT anomaly over the Eurasian continent and the La Niñalike SST anomaly, have contributed to the out-of-phase shift of the two jets. Associated with the dipole SAT anomaly, the tripole meridional temperature gradient pattern is located from the low to high latitudes over the Eurasian continent, and the enhanced MEGR anomaly is located over the regions between the EAPJ and the EASJ. Meanwhile, the anomalous divergence of the E-P flux appears along the region from $40^{\circ}$ to $50^{\circ} \mathrm{N}$, which would result in the equatorward shift of the EAPJ and the poleward shift of the EASJ. Associated with the La Niña-like SST anomaly, the meridional temperature gradient and the STEA anomalies are quite similar to those related to the dipole SAT anomaly. However, the anomalies are more significant in the low latitudes than the high latitudes. This indicates that the SSTI mainly contributes to the meridional shift of the EASJ rather than that of the EAPJ. The pathway of the stationary Rossby wave activity flux anomalies also shows that an eastward Rossby wave packet propagation along the southern portion of the EAPJ associated with the SAT anomaly and along the northern portion of the EASJ associated with the SST anomaly. Correspondingly, the negative height anomalies (anomalous cyclones) over northern Asia and the positive height anomalies (anomalous anticyclones) over the southern Tibetan Plateau and high latitudes would result in the equatorward shift of the EAPJ and the poleward shift of the EASJ.

The relative contributions of the two thermal conditions have been further analyzed by multilinear regression, which emphasizes the role of the dipole SAT anomaly. It should be noted that the dipole SAT variation may be closely related to the thermal conditions over the Tibetan Plateau, which has been mentioned as an important factor for the variations of the two jets, via the associated cyclone-anticyclone anomaly around the Tibetan Plateau (Huang et al. 2015). Given the importance of the dipole SAT variation, the role of the thermal condition of the Tibetan Plateau needs further investigation by numerical experiments.

Acknowledgments. This study is jointly sponsored by the National Key Research and Development Program of China (Grant 2016YFA0600701), National Natural Science Foundation of China (Grants 41575071 and 41775073, 41621005), and the Jiangsu Collaborative Innovation Center for Climate Change.

\section{REFERENCES}

Branstator, G., 2002: Circumglobal teleconnections, the jet stream waveguide, and the North Atlantic Oscillation. J. Climate, 15, 1893-1910, https://doi.org/10.1175/1520-0442(2002)015<1893: CTTJSW $>2.0 . \mathrm{CO} ; 2$.

Carillo, A., P. M. Ruti, and A. Navarra, 2000: Storm tracks and zonal mean flow variability: A comparison between observed and simulated data. Climate Dyn., 16, 219-228, https://doi.org/ $10.1007 / \mathrm{s} 003820050015$.

Chen, H., and Z. Sun, 2003: The effects of Eurasian snow cover anomaly on winter atmospheric general circulation. Part I: Observational studies (in Chinese). Chin. J. Atmos. Sci., 27, 304-316.

Dee, D. P., and Coauthors, 2011: The ERA-Interim reanalysis: Configuration and performance of the data assimilation system. Quart. J. Roy. Meteor. Soc., 137, 553-597, https://doi.org/ 10.1002/qj.828.

Dong, L., P. Guo, and F. Zhang, 2010: Relationship between variations of East Asian Subtropical westerly jet from early summer to midsummer and withdrawal of Meiyu from Jianghuai region (in Chinese). Trans. Atmos. Sci., 33, 74-81.

Eady, E. T., 1949: Long waves and cyclone waves. Tellus, 1, 33-52, https://doi.org/10.3402/tellusa.v1i3.8507.

Eichelberger, S. J., and D. L. Hartmann, 2007: Zonal jet structure and the leading mode of variability. J. Climate, 20, 5149-5163, https://doi.org/10.1175/JCLI4279.1.

Feldstein, S., and S. Lee, 1996: Mechanisms of zonal index variability in an aquaplanet GCM. J. Atmos. Sci., 53, 3541-3556, https:// doi.org/10.1175/1520-0469(1996)053<3541:MOZIVI > 2.0.CO;2.

Gong, D.-Y., J. Yang, S.-J. Kim, Y. Gao, D. Guo, T. Zhou, and M. Hu, 2011: Spring Arctic Oscillation-East Asian summer monsoon connection through circulation changes over the western North Pacific. Climate Dyn., 37, 2199-2216, https:// doi.org/10.1007/s00382-011-1041-1. 
Harris, I., P. D. Jones, T. J. Osborn, and D. H. Lister, 2014: Updated high-resolution grids of monthly climatic observationsThe CRU TS3.10 dataset. Int. J. Climatol., 34, 623-642, https:// doi.org/10.1002/joc.3711.

Held, I. M., and A. Y. Hou, 1980: Nonlinear axially symmetric circulations in a nearly inviscid atmosphere. J. Atmos. Sci., 37, 515-533, https://doi.org/10.1175/1520-0469(1980)037<0515: NASCIA $>2.0 . \mathrm{CO} ; 2$.

Honda, M., J. Inoue, and S. Yamane, 2009: Influence of low Arctic sea-ice minima on anomalously cold Eurasian winters. Geophys. Res. Lett., 36, L08707, https://doi.org/10.1029/ 2008GL037079.

Hoskins, B. J., and P. J. Valdes, 1990: On the existence of stormtracks. J. Atmos. Sci., 47, 1854-1864, https://doi.org/10.1175/ 1520-0469(1990)047<1854:OTEOST>2.0.CO;2.

_ I. N. James, and G. H. White, 1983: The shape, propagation and mean-flow interaction of large-scale weather systems. J. Atmos. Sci., 40, 1595-1612, https://doi.org/10.1175/15200469(1983)040<1595:TSPAMF $>2.0 . \mathrm{CO} ; 2$.

Hou, A. Y., 1998: Hadley circulation as a modulator of the extratropical climate. J. Atmos. Sci., 55, 2437-2457, https://doi.org/ 10.1175/1520-0469(1998)055<2437:HCAAMO > 2.0.CO;2.

Huang, D.-Q., J. Zhu, Y. C. Zhang, and A. N. Huang, 2014: The different configurations of the East Asian polar front jet and subtropical jet and the associated rainfall anomalies over eastern China in summer. J. Climate, 27, 8205-8220, https:// doi.org/10.1175/JCLI-D-14-00067.1.

, — — _ - J. Wang, and X. Y. Kuang, 2015: The impact of the East Asian subtropical jet and polar front jet on the frequency of spring persistent rainfall over southern China in 1997-2011. J. Climate, 28, 6054-6066, https://doi.org/10.1175/ JCLI-D-14-00641.1.

—, A. Dai, J. Zhu, Y. Zhang, and X. Kuang, 2017: Recent winter precipitation changes over eastern China in different warming periods and the associated East Asian jets and oceanic conditions. J. Climate, 30, 4443-4462, https://doi.org/10.1175/ JCLI-D-16-0517.1.

, B. Yang, P. Yan, J. Zhu, and Y. Zhang, 2019: Contributions of different combinations of the IPO and AMO to recent changes in winter East Asian jets. J. Climate, 32, 1607-1626, https://doi.org/10.1175/JCLI-D-18-0218.1.

Huang, R., J. Chen, L. Wang, and Z. Lin, 2012: Characteristics, processes, and causes of the spatio-temporal variabilities of the East Asian monsoon system. Adv. Atmos. Sci., 29, 910942, https://doi.org/10.1007/s00376-012-2015-x.

James, I. N., 1994: Introduction to Circulating Atmospheres. Cambridge University Press, 444 pp., https://doi.org/10.1017/ CBO9780511622977.

Jhun, J.-G., and E.-J. Lee, 2004: A new East Asian winter monsoon index and associated characteristics of the winter monsoon. J. Climate, 17, 711-726, https://doi.org/10.1175/1520-0442 (2004)017<0711:ANEAWM>2.0.CO;2.

Kalnay, E., and Coauthors, 1996: The NCEP/NCAR 40-Year Reanalysis Project. Bull. Amer. Meteor. Soc., 77, 437-471, https:// doi.org/10.1175/1520-0477(1996)077<0437:TNYRP>2.0.CO;2.

Kuang, X., and Y. Zhang, 2006: Impact of the position abnormalities of East Asian subtropical westerly jet on summer precipitation in middle lower reaches of Yangtze River (in Chinese). Plateau Meteor., 25, 382-389.

,,-- D. Huang, and Y. Huang, 2016: Regionality of recordbreaking low temperature events in China and its associated circulation. Climate Dyn., 46, 1719-1731, https://doi.org/ 10.1007/s00382-015-2670-6.
Lee, S., 1997: Maintenance of multiple jets in a baroclinic flow. J. Atmos. Sci., 54, 1726-1738, https://doi.org/10.1175/15200469(1997)054<1726:MOMJIA > 2.0.CO;2.

Lehmann, J., D. Coumou, K. Frieler, A. V. Eliseev, and A. Levermann, 2014: Future changes in extratropical storm tracks and baroclinicity under climate change. Environ. Res. Lett., 9, 084002, https://doi.org/10.1088/1748-9326/9/8/084002.

Li, Camille, and J. J. Wettstein, 2012: Thermally driven and eddydriven jet variability in reanalysis. J. Climate, 25, 1587-1596, https://doi.org/10.1175/JCLI-D-11-00145.1.

Li, Chao, and Q. Zhang, 2013: The circulation of spring precipitation anomalies over the Yangtze River valley and their response to the preceding SSTA (in Chinese). Acta Meteor. Sin., 71, 452-461.

Li, C.-Y., Z. Wang, S. Lin, and H. Zhuo, 2004: The relationship between East Asian summer monsoon activity and northward jump of the upper westerly jet location (in Chinese). Chin. J. Atmos. Sci., 28, 641-658.

Li, L., and Y. Zhang, 2014: Effects of different configurations of the East Asian subtropical and polar front jets on precipitation during the mei-yu season. J. Climate, 27, 6660-6672, https:// doi.org/10.1175/JCLI-D-14-00021.1.

Li, W., W. Guo, B. Qiu, Y. Xue, P.-C. Hsu, and J. Wei, 2018: Influence of Tibetan Plateau snow cover on East Asian atmospheric circulation at medium-range time scales. Nat. Commun., 9, 4243, https://doi.org/10.1038/s41467-018-06762-5.

Liao, Q., S. Gao, H. Wang, and S. Tao, 2004: Interannual variation of summer subtropical westerly jet in East Asia and its impacts on the climate anomalies of East Asia summer monsoon (in Chinese). Chin. J. Geophys., 47, 12-21, https://doi.org/10.1002/ cjg2.449.

Liao, Z., and Y. Zhang, 2013: Concurrent variation between the East Asian subtropical jet and polar front jet during persistent snowstorm period in 2008 winter over southern China. J. Geophys. Res. Atmos., 118, 6360-6373, https://doi.org/ 10.1002/jgrd.50558.

Lin, Z., and R. Lu, 2005: Interannual meridional displacement of the East Asian upper-tropospheric jet stream in summer. $A d v$. Atmos. Sci., 22, 199-211, https://doi.org/10.1007/BF02918509.

Liu, Y., L. Wang, W. Zhou, and W. Chen, 2014: Three Eurasian teleconnection patterns: Spatial structures, temporal variability, and associated winter climate anomalies. Climate Dyn., 42, 2817-2839, https://doi.org/10.1007/s00382-014-2163-z.

Lorenz, D. J., and D. L. Hartmann, 2001: Eddy-zonal flow feedback in the Southern Hemisphere. J. Atmos. Sci., 58, 33123327, https://doi.org/10.1175/1520-0469(2001)058<3312: EZFFIT $>2.0 . \mathrm{CO} ; 2$.

$\longrightarrow$, and — 2003: Eddy-zonal flow feedback in the Northern Hemisphere winter. J. Climate, 16, 1212-1227, https://doi.org/ 10.1175/1520-0442(2003)16<1212:EFFITN >2.0.CO;2.

Lu, J., G. Chen, and D. M. W. Frierson, 2010: The position of the midlatitude storm track and eddy-driven westerlies in aquaplanet AGCMs. J. Atmos. Sci., 67, 3984-4000, https://doi.org/ 10.1175/2010JAS3477.1.

Lu, R., 2004: Associations among the components of the East Asian summer monsoon system in the meridional direction. J. Meteor. Soc. Japan, 82, 155-165, https://doi.org/10.2151/ jmsj.82.155.

_ Z Z. Lin, and Y. Zhang, 2013: Variability of the East Asian upper-tropospheric jet in summer and its impacts on the East Asian monsoon (in Chinese). Chin. J. Atmos. Sci., 37, 331-340.

Lunkeit, F., K. Fraedrich, and S. E. Bauer, 1998: Storm tracks in a warmer climate: Sensitivity studies with a simplified global 
circulation model. Climate Dyn., 14, 813-826, https://doi.org/ $10.1007 / \mathrm{s} 003820050257$.

Luo, X., and Y. Zhang, 2015: The linkage between upper-level jet streams over East Asia and East Asian winter monsoon variability. J. Climate, 28, 9013-9028, https://doi.org/10.1175/ JCLI-D-15-0160.1.

Ma, Y., W. Chen, and L. Wang, 2011: A comparative study of the interannual variation of summer rainfall anomalies between the Huaihe Meiyu season and the Jiangnan Meiyu season and their climate background (in Chinese). Acta Meteor. Sin., 69, 334-343.

Mori, M., M. Watanabe, H. Shiogama, J. Inoue, and M. Kimoto, 2014: Robust Arctic sea-ice influence on the frequent Eurasian cold winters in past decades. Nat. Geosci., 7, 869-873, https:// doi.org/10.1038/ngeo2277.

Murakami, M., 1979: Large-scale aspects of deep convective activity over the GATE area. Mon. Wea. Rev., 107, 994-1013, https:// doi.org/10.1175/1520-0493(1979)107<0994:LSAODC >2.0.CO;2.

Oh, H., J. G. Jhun, K. J. Ha, and K. H. Seo, 2017: Combined effect of the east Atlantic/west Russia and western Pacific teleconnections on the East Asian winter monsoon. Asia-Pac. J. Atmos. Sci., 53, 273-285, https://doi.org/10.1007/s13143-017-0030-7.

Panetta, R. L., 1993: Zonal jets in wide baroclinically unstable regions: Persistence and scale selection. J. Atmos. Sci., 50, 2073-2106, https://doi.org/10.1175/1520-0469(1993)050<2073: ZJIWBU $>2.0 . \mathrm{CO} ; 2$.

Pena-Ortiz, C., D. Gallego, P. Ribera, P. Ordonez, and M. Del Carmen Alvarez-Castro, 2013: Observed trends in the global jet stream characteristics during the second half of the 20th century. J. Geophys. Res. Atmos., 118, 2702-2713, https://doi.org/ 10.1002/jgrd.50305.

Rayner, N. A., 2003: Global analyses of sea surface temperature, sea ice, and night marine air temperature since the late nineteenth century. J. Geophys. Res., 108, 4407, https://doi.org/ 10.1029/2002JD002670.

Ren, X., Y. Zhang, and Y. Xiang, 2008: Connections between wintertime jet stream variability, oceanic surface heating, and transient eddy activity in the North Pacific. J. Geophys. Res., 113, D21119, https://doi.org/10.1029/2007JD009464.

— , X. Yang, and C. Chu, 2010: Seasonal variations of the synoptic-scale transient eddy activity and polar front jet over East Asia. J. Climate, 23, 3222-3233, https://doi.org/10.1175/ 2009JCLI3225.1.

,-- T. T. Zhou, and J. Fang, 2011: Diagnostic comparison of wintertime East Asian subtropical jet and polar-front jet: Large-scale characteristics and transient eddy activities. Acta Meteor. Sin., 25, 21-33, https://doi.org/10.1007/s13351-011-0002-2.

Sakai, K., and R. Kawamura, 2009: Remote response of the East Asian winter monsoon to tropical forcing related to El NiñoSouthern Oscillation. J. Geophys. Res., 114, D06105, https:// doi.org/10.1029/2008JD010824.

Schiemann, R., D. Lüthi, and C. Schär, 2009: Seasonality and interannual variability of the westerly jet in the Tibetan Plateau region. J. Climate, 22, 2940-2957, https://doi.org/10.1175/ 2008JCLI2625.1.

Seidel, D., Q. Fu, W. Randel, and T. Reichler, 2008: Widening of the tropical belt in a changing climate. Nat. Geosci., 1, 21-24, https://doi.org/10.1038/ngeo.2007.38.

Shen, B. Z., Z. D. Lin, R. Y. Lu, and Y. Lian, 2011: Circulation anomalies associated with interannual variation of early- and late-summer precipitation in northeast China. Sci. China Earth Sci., 54, 1095-1104, https://doi.org/10.1007/s11430-0114173-6.
Si, D., Y. Ding, and Y. Liu, 2009: Decadal northward shift of the Meiyu belt and the possible cause. Chin. Sci. Bull., 54, 4742-4748.

Sun, C., and S. Yang, 2012: Persistent severe drought in southern China during winter-spring 2011: Large-scale circulation patterns and possible impacting factors. J. Geophys. Res., 117, D10112, https://doi.org/10.1029/2012JD017500.

Takaya, K., and H. Nakamura, 2001: A formulation of a phaseindependent wave-activity flux for stationary and migratory quasigeostrophic eddies on a zonally varying basic flow. J. Atmos. Sci., 58, 608-627, https://doi.org/10.1175/1520-0469 (2001)058<0608:AFOAPI $>2.0 . \mathrm{CO} ; 2$.

, and - 2013: Interannual variability of the East Asian winter monsoon and related modulations of the planetary waves. J. Climate, 26, 9445-9461, https://doi.org/10.1175/JCLID-12-00842.1.

Wang, B., R. Wu, and X. Fu, 2000: Pacific-East Asian teleconnection: How does ENSO affect East Asian climate? J. Climate, 13, 1517-1536, https://doi.org/10.1175/1520-0442 (2000)013<1517:PEATHD>2.0.CO;2.

Wang, D., and Coauthors, 2009: A preliminary analysis of features and causes of the snow storm event over the southern areas of China in January 2008. Acta Meteor. Sin., 23, 374-386.

Wang, L., W. Chen, W. Zhou, and R. Huang, 2009: Interannual variations of East Asian trough axis at $500 \mathrm{hPa}$ and its association with the East Asian winter monsoon pathway. J. Climate, 22, 600-614, https://doi.org/10.1175/2008JCLI2295.1.

, — - R. Feng, and J. Liang, 2011: The seasonal march of the North Pacific oscillation and its association with the interannual variations of China's climate in boreal winter and spring (in Chinese). Chin. J. Atmos. Sci., 35, 393-402.

Watanabe, M., 2004: Asian jet waveguide and a downstream extension of the North Atlantic Oscillation. J. Climate, 17, 46744691, https://doi.org/10.1175/JCLI-3228.1.

Xiang, Y., and X. Yang, 2012: The effect of transient eddy on interannual meridional displacement of summer East Asian subtropical jet. Adv. Atmos. Sci., 29, 484-492, https://doi.org/ 10.1007/s00376-011-1113-5.

Xiao, C., and Y. Zhang, 2012: The East Asian upper-tropospheric jet streams and associated transient eddy activities simulated by a climate system model BCC_CSM1.1. Acta Meteor. Sin., 26, 700-716, https://doi.org/10.1007/s13351-012-0603-4.

Xuan, S., Q. Zhang, and S. Sun, 2011: Relationship between the monthly variation of the East Asia westerly jet and the Huaihe River valley rainfall anomaly in summer (in Chinese). Climate Environ. Res., 16, 231-242.

Xue, D., and Y. Zhang, 2017: Concurrent variations in the location and intensity of the Asian winter jet streams and the possible mechanism. Climate Dyn., 49, 37-52, https://doi.org/10.1007/ s00382-016-3325-y.

Yang, S., K. M. Lau, and K. M. Kim, 2002: Variations of the East Asian jet stream and Asian-Pacific-American winter climate anomalies. J. Climate, 15, 306-325, https://doi.org/10.1175/ 1520-0442(2002)015<0306:VOTEAJ > 2.0.CO;2.

- - , S.-H. Yoo, J. L. Kinter, K. Miyakoda, and C.-H. Ho, 2004: Upstream subtropical signals preceding the Asian summer monsoon circulation. J. Climate, 17, 4213-4229, https:// doi.org/10.1175/JCLI3192.1.

Yim, B. Y., H. S. Min, and J.-S. Kug, 2016: Inter-model diversity in jet stream changes and its relation to Arctic climate in CMIP5. Climate Dyn., 47, 235-248, https://doi.org/10.1007/s00382-0152833-5.

Zhang, J., T. Zhou, R. Yu, and X. Xin, 2009: Atmospheric water vapor transport and corresponding typical anomalous spring 
rainfall patterns in China (in Chinese). Chin. J. Atmos. Sci., 33, 121-134.

Zhang, R., A. Sumi, and M. Kimoto, 1996: Impact of El Niño on the East Asian monsoon: A diagnostic study of the'86/87 and'91/ 92 events. J. Meteor. Soc. Japan, 74, 49-62, https://doi.org/ 10.2151/jmsj1965.74.1_49.

Zhang, Y., K. R. Sperber, and J. S. Boyle, 1997: Climatology and interannual variation of the East Asian winter monsoon: Results from the 1979-95 NCEP/NCAR reanalysis. Mon. Wea. Rev., 125, 2605-2619, https://doi.org/10.1175/1520-0493 (1997) $125<2605$ :CAIVOT $>2.0 . C O ; 2$.

Zhang, Y.-C., and D. Huang, 2011: Has the East Asian westerly jet experienced a poleward displacement in recent decades? Adv. Atmos. Sci., 28, 1259-1265, https://doi.org/10.1007/ s00376-011-9185-9.

_, X. Kuang, W. Guo, and T. Zhou, 2006: Seasonal evolution of the upper-tropospheric westerly jet core over East Asia. Geophys. Res. Lett., 33, L11708, https://doi.org/10.1029/ 2006GL026377.
D. Wang, and X. Ren, 2008: Seasonal variation of the meridional wind in the temperate jet stream and its relationship to the Asian monsoon (in Chinese). Acta Meteor. Sin., 66, 707-715.

Zhou, T.-J., and R.-C. Yu, 2005: Atmospheric water vapor transport associated with typical anomalous summer rainfall patterns in China. J. Geophys. Res., 110, D08104, https://doi.org/ 10.1029/2004JD005413.

— , and L. Zou, 2010: Understanding the predictability of East Asian summer monsoon from the reproduction of land-sea thermal contrast change in AMIP-type simulation. J. Climate, 23, 6009-6026, https://doi.org/10.1175/2010JCLI3546.1.

Zhu, J., D.-Q. Huang, Y. Dai, and X. Chen, 2016: Recent heterogeneous warming and the associated summer precipitation over eastern China. Theor. Appl. Climatol., 123, 619-627, https:/doi.org/10.1007/s00704-015-1380-7.

- - , P.-W. Yan, Y. Huang, and X.-Y. Kuang, 2017: Can reanalysis datasets describe the persistent temperature and precipitation extremes over China? Theor. Appl. Climatol., 130, 655-671, https://doi.org/10.1007/s00704-016-1912-9. 